\title{
Desenvolvimento de Aplicativo Móvel para auxílio à Assistência à Saúde na cidade de Alto Araguaia-MT
}

\author{
Daniela de O. Bastos, Wesley B. Thereza, Dárley D. de Almeida \\ Departamento de Ciência da Computação \\ Universidade do Estado do Mato Grosso (UNEMAT) - Alto Araguaia, MT - Brasil \\ \{danyelaaia@gmail.com, wesley@unemat.br, darleydalmeida@gmail.com
}

\begin{abstract}
The Information and Communication Technologies have advanced and its study also, facilitating the population the comprehension and the effective use of the technological tools for the optimization of the activities and daily necessities. This paper aims to present an alternative to access to information and programming of Health Care that is offered in the city of Alto Araguaia-Mato Grosso. The information and programming will be administered by the Health Department of Alto Araguaia and will be made available through a mobile application, which the population can access through smartphones.
\end{abstract}

Resumo. As Tecnologias de Informação e Comunicação têm avançado e seu estudo também, facilitando à população a compreensão e o uso eficaz das ferramentas tecnológicas para otimização das atividades e necessidades cotidianas. Este trabalho tem como objetivo apresentar uma alternativa ao acesso as informações e programação da Assistência à Saúde que é ofertada na cidade de Alto Araguaia-Mato Grosso. As informações e programação serão administradas pela Secretaria de Saúde de Alto Araguaia e serão disponibilizadas por meio de aplicativo móvel, que a população poderá acessar por meio de smartphones.

\section{Introdução}

O desenvolvimento das Tecnologias de Informação e Comunicação (TICs) tem provido aumento na qualidade de vida da população, sendo no fornecimento de informações ou aplicações para a área financeira, profissional, esportiva, pessoal entre outras.

O objetivo deste trabalho é apresentar parte do desenvolvimento de um aplicativo para plataformas móveis, que auxilie a Secretaria de Saúde da cidade de Alto AraguaiaMT a fornecer informações e programar o acesso às UBSs para a população local, baseando-se no referencial teórico sobre aplicativos que auxiliaram populações locais, em várias cidades/Estados do Brasil, ao acesso de informações úteis e atuais.

\section{Desenvolvimento}

A utilização de aplicativos para dispositivos móveis tem proporcionado excelentes resultados em diferentes áreas. Existem diversos frameworks para desenvolvimento de aplicações relacionados a saúde, e o uso de dispositivos móveis é favorecido por três fatores: o aumento das doenças crônicas, diminuição do acesso aos cuidados clínicos, e as inovações no âmbito das tecnologias móveis [1]. Existem várias estratégias e ferramentas de desenvolvimento que podem ser utilizados para a criação aplicativos para dispositivos móveis, dentre os quais escolhemos o desenvolvimento híbrido com uso do 
framework Ionic, a suíte de desenvolvimento Firebase e a metodologia de Desenvolvimento Guiado por Testes (Test Driven Develpment - TDD).

O desenvolvimento híbrido está sendo adotado por ser uma abordagem de desenvolvimento moderna e capaz de prover rapidez, pois um único processo de desenvolvimento gera aplicativos de várias plataformas. Isto é possível devido ao uso combinado de diferentes frameworks disponíveis e linguagens de programação web como HTML, CSS3 e Javascript, por exemplo. E graças aos avanços evolutivos dos frameworks, aplicativos desenvolvidos com abordagem híbrida apresentam desempenho e Experiência de Usuário (UX) análoga ao de aplicativos desenvolvidos com abordagem nativa [2].

No contexto de desenvolvimento híbrido, o framework Ionic foi escolhido por ser uma estrutura de desenvolvimento de aplicações móveis HTML5 voltada para uma construção de aplicações móveis híbridos. Os aplicativos híbridos são, essencialmente, pequenos sites que funcionam em um shell do navegador em um aplicativo que oferece acesso à camada da plataforma nativa. A maior parte de um aplicativo construído com o Iônic será escrito em HTML, Javascript/typescript e CSS. O Ionic também usa o AngularJS para uma grande parte da funcionalidade principal da estrutura. O Ionic pode ser entendido como uma camada que envolve o Apache Cordova, aquele que disponibiliza uma maneira na qual as aplicações criadas utilizando tecnologia web como HTML, CSS e JavaScript possam acessar recursos nativos das plataformas mobile na qual desejamos suportar [3]-[4].

Outro recurso utilizado é o Firebase [5], conforme a sua página de acesso, é caracterizado como uma plataforma para a construção de aplicativos móveis e web, por meio de ferramentas e infraestruturas que objetivam desenvolver aplicativos com qualidade, em que pode agrupar vários serviços importantes, os quais merecem destaque: o sistema de análise (Firebase Analytics), sistema de autenticação de usuário (Firebase Auth), armazenamento (Firebase Storage), banco de dados (Firebase Realtime Database), hospedagem (Firebase Hosting) entre outros.

O projeto será desenvolvido baseando-se na metodologia de Desenvolvimento Guiado por Testes (Test Driven Develpment - TDD). Essa metodologia baeia-se na ideia de "testar antes" (test-first) e pode ser definida como: "um processo em que o desenvolvedor começa a implementação de uma nova funcionalidade pelo teste e deve, o tempo todo, fazer de tudo para que seu código fique simples e com qualidade" [6]. A metodologia TDD também pode ser entendida como uma maneira de testar antes de ver o programa desenvolvido, observando os erros de lógica no código e definição de requisitos para que o software seja disponibilizado para uso conforme com o que se almejado [7].

\section{O Município de Aplicação do Projeto}

De acordo com o IBGE, as informações do último censo (2019) sobre a cidade de Alto Araguaia - MT, a população estava no número de 15.644 pessoas, estimando-se para 2019 o número de 19.044 pessoas [8].

As informações no site da prefeitura sobre a secretaria de saúde do município, dispõe sobre as ações e serviços de saúde que são ofertados, assim como a responsabilidade de formular e implantar políticas, programas e projetos que visem à promoção de uma saúde de qualidade aos usuários do Sistema Único de Saúde (SUS). Da qual, a atuação a promoção junto à população local, com campanhas preventivas de doenças e educação sanitária, bem como a garantia de distribuição de medicamentos para 
a população de baixa renda e a execução de serviços de vigilância sanitária e epidemiológica do município são ofertadas.

\section{Considerações Finais}

O desenvolvimento e o uso de aplicativos móveis está a cada dia mais acessível a população que se dedica em transformar a realidade social em que está inserida, provocar incremento na qualidade de vida da população entre outras possibilidades. Foram apresentadas neste trabalho as ferramentas que serão utilizadas e a descrição de um projeto de aplicativo móvel de cunho social que tem o objetivo de prover melhoria na comunicação entre a Secretaria Municipal de Saúde e a população local.

Como citado, o presente trabalho tem sido desenvolvido em caráter multidisciplinar, no âmbito das disciplinas de Desenvolvimento de Aplicativos para Dispositivos Móveis e Engenharia de Software no curso de Bacharelado em Ciência da Computação da UNEMAT, campus de Alto Araguaia-MT, com objetivo primeiro de consolidar o conhecimento dessas disciplinas através da combinação da teoria e da prática, e, por conseguinte, promover um bem social através da aplicação futura do aplicativo em questão após seu desenvolvimento, teste e distribuição, pois como visto na contextualização da cidade Alto Araguaia, a Secretaria Municipal de Saúde tem que atender aproximadamente 20 mil munícipes, provendo assistência à saúde, acesso a informações e consequente qualidade de vida.

\section{Referências}

[1] Morris, M. E. Motivating change with mobile: seven guidelines.interactions, v. 19, n. 3, p. 26-31. 2012.

[2] Moura, I. e Araújo, A., Desenvolvimento de Aplicativos Híbridos baseado em Arquitetura Orientada a Serviços. 2017.

[3] IONIC. A litle about Ionic. 2018. Disponível em: < https://www.alura.com.br/artigos/ 5-vantagens-do-ionic-para-desenvolver-suas-aplicacoes-mobile>. Acesso em: 12 set 2019.

[4] Junior, L. 5 vantagens do Ionic para desenvolver suas aplicações mobile. 2016. Disponível em: <https://www.alura.com.br/artigos/5-vantagens-do-ionic-paradesenvolver-suas-aplicacoes-mobile > . Acesso em: 29 set. 2018.

[5] Firebase. Disponível em: < https://firebase.google.com/docs?hl=pt-br >. Acesso em $11 / 09 / 2019$.

[6] Gomes, A. F. Agile - Desenvolvimento de software com entregas frequentes e foco no valor de negócio. 1. ed. São Paulo: Casa do Código, 2013.

[7] Lopes, C. Test Driven Development na Prática. 1. ed. Rio de Janeiro: Ciência Moderna, 2012.

[8] IBGE. Estimativas da População. Disponível em: < https://www.ibge.gov.br/ estatisticas/sociais/populacao/9103-estimativas-de-populacao.html?=\&t=resultados >. Acesso em 13/09/2019. 